\title{
General approach to velocardiofacial anomalies: a pediatric case presenting with Fallot tetralogy
}

\author{
Aysu Turkmen Karaagac ${ }^{1}$, Ayse Inci Yildirim² \\ ${ }^{1}$ Department of Pediatrics, Kartal Kosuyolu Training and Research Hospital, Istanbul, Turkey; \\ ${ }^{2}$ Department of Pediatric Cardiology, Kartal Kosuyolu Training and Research Hospital, Istanbul, Turkey
}

\begin{abstract}
Velocardiofacial syndrome (VCFS), also known as "Shprintzen syndrome" or "22q11.2 deletion syndrome" is an autosomal dominant genetic disorder with a wide range of phenotypical findings. It is majorly characterized by cleft palate, dysmorphic face, conotruncal cardiac anomalies, growth retardation, neurologic disorders and learning disabilities. Our case was the first child of her family and she had a cleft palate, dysmorphic face, tetralogy of Fallot (TOF), growth retardation and a mild neuromotor developmental delay. It is important to recognize this syndrome and inform the family about the probable future health problems of their babies as early as possible. Genetic counselling is crucial for the subsequent pregnancies. Therefore, we wanted to review the literature about the differential diagnosis and genetics of velocardiofacial anomalies.
\end{abstract}

Key words: Conotruncal cardiac anomaly; dysmorphic face; genetic counselling; 22q11 deletion.

$\mathrm{V}$ elocardiofacial anomalies are related to the microdeletions on the long arm of chromosome 22 and characterized by several different combinations of clinical features as cleft palate, dysmorphic facial appearance, conotruncal cardiac anomalies, ophtalmic disorders, ear problems, immunologic deficiencies, hematologic and/or renal abnormalities, musculoskeletal problems, neurologic and psychologic disorders $[1,2]$. The frequency of Velocardiofacial syndrome (VCFS) among all surviving newborns in the United States is about 1:2000 [3].

\section{CASE REPORT}

Z.T. was a 11-month-old female baby. She was born at the $37^{\text {th }}$ week of gestation weighing 2650 gr, and delivered by a cesarean section. She was followed in the neonatal intensive care unit for 2 weeks due to the respiratory insufficiency, cleft palate and feeding difficulty. At the first hospital visit after her discharge, pulmonary valvular stenosis and tetralogy of Fallot (TOF) were diagnosed on her echocardiograms. Balloon valvuloplasty was performed 


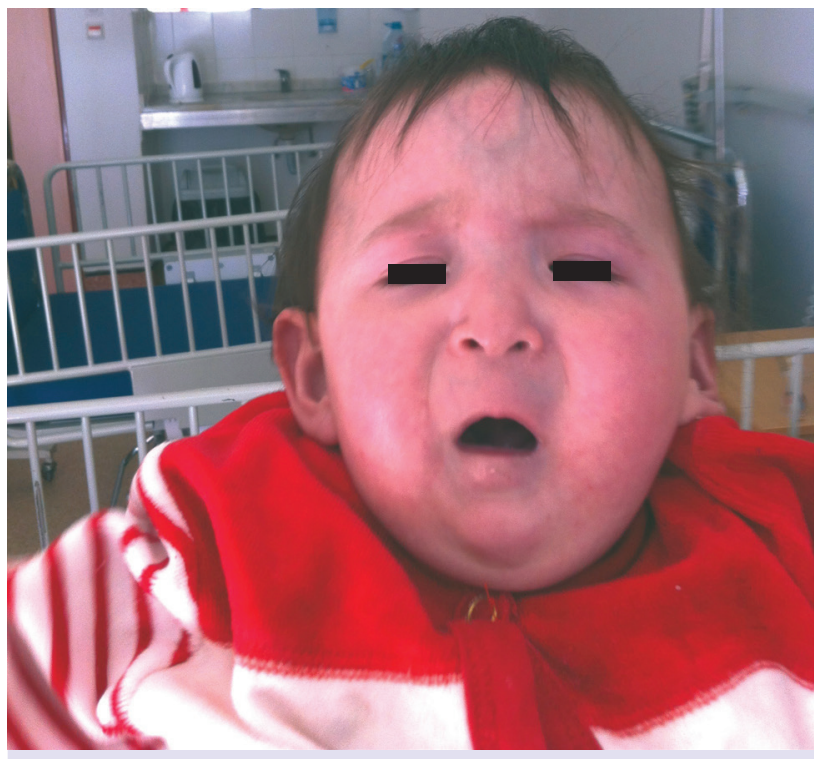

FIGURE 1. Facial dysmorphism in velocardiofacial syndrome.

when she was 4 month- old. She was referred to our hospital for the surgical correction of her cardiac anomalies at the 11 months. On her physical examination in our clinic, her body weight was 6300 gr. ( $<3$ percentile), height $62 \mathrm{~cm}$. ( $<3$ percentile) and head circumference, $41 \mathrm{~cm}$. (<3 percentile). She had a wide forehead, low nasal bridge, cleft palate, micro/retrognathia, hypoplastic maxilla and hypertelorism (Figure 1). Her heart rate was $130 \mathrm{bpm}$, respiratory rate was 32 breaths per minute with an oxygen saturation of $82 \%$ while breathing room air and her systemic blood pressure was $80 / 50 \mathrm{mmHg}$. She had bilateral sibilant rales and $2 / 6$ systolic murmur at the pulmonic area on auscultation. Her liver was $3 \mathrm{~cm}$. palpable below the subcostal margin and the spleen was nonpalpable. She had 3 hemangiomas with the diameters of 3 to $5 \mathrm{~cm}$ on her back. Her musculoskeletal and the genital examinations were within normal limits.

The mother of Z.T. was 26 and the father was 28 years old. There was no consanguinity between them and they had no dysmorphic facial appearance or any systemic illnesses. The mother had not received regular medical follow- ups during her pregnancy. She had never used tobacco or alcohol. There was no history of drug use or exposure to Xray after she became pregnant. She had no history of infection, abortus or stillbirth, either. Their first degree relatives had not any congenital anomalies.

Biochemical and microbiological examinations of Z.T. showed mild infection with a white blood cell count of $13500 / \mathrm{mm} 3, \mathrm{C}$ reactive protein level of $2 \mathrm{mg} / \mathrm{dl}$ and 64\% neutrophil dominancy (63\%) on the peripheral blood smear, iron deficiency anemia and hypocalcemia with a serum calcium level of $7.3 \mathrm{mg} / \mathrm{dl}$. Her $25 \mathrm{OH}-\mathrm{D}$ level was low $(10 \mathrm{ng} / \mathrm{ml})$, parathyroid and thyroid hormone levels were nor$\mathrm{mal}(15.2 \mathrm{pg} / \mathrm{ml}$ and $2.1 \mathrm{IU} / \mathrm{ml}$, respectively). After treatment with calcium and vitamin $\mathrm{D}$, her serum calcium levels have sustained within normal ranges. Serologic test results for toxoplasma, rubella and cytomegalovirus (TORCH) were negative. Her cardiothoracic ratio increased and the cardiac apex was elevated on the chest X-ray. On her echocardiogram, there was perimembranous ventricular septal defect, pulmonary stenosis, straddling tricuspid valve with a moderate degree of incompetence, patent ductus arteriosus, 50\% dextroposition of aorta, tetralogy of Fallot and coronary arterial fistula on the ventricular septum. Abdominal ultrasonograms were normal except for a mild hepatomegaly.

As there were two afebrile seizure attacks in her neonatal history, electroencephalography (EEG) was performed. EEG reports indicated that there were sharp wave activities on the frontocentral, centrooccipital and temporooccipital regions of the left serebral hemisphere in relation with the centrooccipital region of the right cerebral hemisphere. Ophthalmic and audiological examinations of Z.T. were unremarkable. Cranial and spinal magnetic resonance examinations (MRI) showed mild dilatation of the lateral ventricules and a lipoma on the philum terminale.

The karyotype analysis of our case was reported as 46, XX. On her fluorescence in situ hybridization (FISH) analysis performed using DG (22q11) probe, deletion of band 11 on the long arm of chromosome 22 was detected.

After a successful total correction of TOF, tricuspid valvuloplasty and PDA ligation operations, she was discharged from our hospital on the twentieth postoperative day. We informed the family about the necessity of multidisciplinary approach for the children with VCFS to deal with their gastrointestinal, neurological, hematological, endocrinological, 
ophthalmic and the psychological problems in the future. We directed them for genetic counseling for the subsequent pregnancies. Z.T. underwent a plastic surgery for the correction of her cleft palate. She is 2 years old now and healthy.

The written consent of the family was taken for the publication of this case.

\section{DISCUSSION}

Shprintzen and colleagues first described the VCFS in 1981 and Scambler defined the microdeletions on the long arm of $22^{\text {nd }}$ chromosome as its main pathology in 1992. VCFS may present with several different combinations of phenotypical and clinical features $[1,4]$.

VCFS is also known as "DiGeorge syndrome", however the severity of immune deficiency differs between rhese two entities. In "complete DiGeorge syndrome", there are recurrent, severe upper/lower tract infections due to the abscence of thymus and hypocalcemic convulsions may take place as a result of parathyroid aplasia [2,3]. Our case had a thymus gland and no history of recurrent severe respiratory tract infections. She had a mild hypocalcemia, but her parathyroid hormone level was normal. Several studies have shown that $36 \%$ of the children with VCFS have severe growth retardation (weight and height below 3rd percentile) [2]. Furthermore, congestive heart failure secondary to the congenital cardiac anomalies may lead to the development of edema on the small bowel surface and malabsorption, which results in nutrient deficiency in these children [5]. Our case also had a severe growth retardation, vitamin D deficiency, iron deficiency and hypocalcemia as a result of feeding difficulty due to the cleft palate, congestive heart failure and malabsorption. After administration of anticongestive therapy, antibiotherapy, fluid and nutritional support, our patient started to gain weight of $20-30 \mathrm{gr} /$ day and her vitamin $\mathrm{D}$ and calcium levels returned to normal.

Wang and colleagues performed phenotypical analysis of the children with VCFS by using three dimensional computed tomography and reported that $95 \%$ of these children had facial, gnathial and/ or palatal abnormalities. Palatal anomalies seen in $70 \%$ of these children were mostly the cleft palate of complete type and rarely of submucosal type together with a bifid uvula and velopharyngeal insufficiency [6]. Our case had a submucosal cleft palate, bifid uvula, micro/retrognathia, wide prominent forehead, low nasal bridge and hypertelorism. We directed the family to a plastic surgery clinic and a palatal obturator was provided until accomplishment of her cardiac surgery. As the children with velopharyngeal insufficiency have short soft palate and hypotonic velopharyngeal muscles, they have difficulty in speaking and swallowing, which create a tendency to aspiration and speech disorders [7]. Our case also had a short soft palate, difficulty in speaking and swallowing and her endoscopic examination in the ear-nose and throat clinic (ENT) showed velopharyngeal insufficiency. $\mathrm{Ha}$ and colleagues reported that the repair of the cleft palate after 18 months of age would lead to a higher risk of developing articulatory speech problems resulting in the need for more speech therapy [8]. Therefore, the children with VCFS should be consultated with plastic surgeons, orthodontists, ENT specialists and speech therapists for the monitorization and resolution of their facial and velopharyngeal problems as early as possible $[6,7,8]$. The cleft palate of our case was corrected in the fifteenth postnatal month and she has being followed by ENT specialists and speech therapists in a university hospital since then.

Conotruncal cardiovascular anomalies diagnosed in $75 \%$ of the VCFS cases, especially in those with $22 \mathrm{q} 11$ deletion, are the main causes of morbidity and mortality. The most common cardiac anomalies are aortic arch anomalies (28\%), pulmonary atresia and ventricular septal defect (23\%), ventricular septal defect (21\%), tetralogy of Fallot (15\%) and truncus arteriosus (13\%) [1, 9]. Rouch and colleagues screened 217 cases with aortic arch anomalies and found $22 \mathrm{q} 11.2$ deletions in patients with subclavian artery anomalies $(n=38 / 47 ; 81 \%)$, right $(n=24 / 52 ; 46 \%)$, and left aortic $(n=35 / 118$; $30 \%)$ arches [10].

Fallot tetralogy is not a common cardiac pathology in VCFS with 22q11 deletion. Maeda and colleagues examined 212 patients with TOF and found $22 \mathrm{q} 11$ deletion only in 28 (13\%) of VCFS patients [11].

Our case had tetralogy of Fallot, perimembra- 
nous ventricular septal defect, pulmonary stenosis, straddling tricuspid valve with a moderate degree of incompetence, patent ductus arteriosus, 50\% dextroposition of aorta, and coronary arterial fistula on the ventricular septum. These anomalies were corrected by total correction of TOF, tricuspid valvuloplasty and PDA ligation operations.

Amelswoort and colleagues performed quantitative MRI studies and reported that the VCFS cases had differences in their brain anatomies affecting the midline structures (septum pallicidum, corpus callosum), the cerebellum, white and grey matters of the temporal and left frontal regions. Fusion in the cervical vertebra, and narrowing of the spinal canal may also be detected. These abnormalities may partially explain the cognitive profile and the neuropsychiatric problems encountered in VCFS cases. Therefore, it is necessary to perform cranial and spinal MRIs of the people with VCFS $[12,13]$. As our case had two afebrile seizure attacks in the neonatal period with a mild neurodevelopmental delay, we performed cranial and spinal MRI and the EEG studies. We informed the family about the possible future problems of their child as neuromotor retardation, learning disability, speech disorder and psychiatric problems (psychosis, schisophrenia). They have been attending to a neurologist, a psychiatrist, a psychologist and a speech therapist since then.

On their urogenital system examinations, 35\% of the children with VCFS showed urinary system abnormalities such as renal agenesis, multicystic kidneys, urolithiasis, horseshoe kidneys, hydronephrosis, vesicoureteral reflux or double collecting system, Besides they had 20-30\% inguinal hernia (20-30\%), hypospadias (8\%), and undescended testicle $(\mathrm{s})(6 \%)[2,3]$. Therefore, the urogenital system examinations should be carefully made and the urinary ultrasonography should be performed in the children with VCFS. The urogenital system examination of our case was normal as well as her urinary system ultrasonography.

The microdeletions on the long arm of chromosome 22, leading to VCFS, are usually sporadic and affect a region containing 30 genes in $90 \%$ of the cases. However, in $7-8 \%$ of VCFS cases microdeletions may take place in smaller regions containing 20-25 genes, which explain the high phenotypical variations of VCFS cases $[14,15]$. It is important to perform genetic analysis of both parents of a child with VCFS even if they don't have facial dysmorphism or history of a cardiovascular disease. As the VCFS is an autosomal dominant disorder, a deletion in the chromosome of any parent will increase the risk of VCFS with more dramatical clinical presentations in the subsequent pregnancies [16]. The FISH analysis of our case revealed $22 \mathrm{q} 11$ deletion, so we directed the family to a university hospital for genetic counselling. The FISH analysis results of the parents were normal and they were informed about the importance of amniocentesis for the subsequent pregnancies.

As a result, VCFS requires a multidisciplinary approach to deal with multiple systemic anomalies. Therefore, it is vital to recognize the syndrome and inform the family as early as possible to get good results from the necessary interventions.

Conflict of Interest: No conflict of interest was declared by the authors.

Financial Disclosure: The authors declared that this study has received no financial support.

\section{REFERENCES}

1. Digilio M, Marino B, Capolino R, Dallapiccola B. Clinical manifestations of Deletion 22q11.2 syndrome (DiGeorge/Velo-Cardio-Facial syndrome). Images Paediatr Cardiol 2005;7:23-34.

2. Shprintzen RJ. Velocardiofacial Syndrome. In: Cassidy SB, Allanson JE (eds). Manag of Genetic Syndr. New Jersey: WilleyLiss 2005:615-31.

3. Shprintzen RJ. Velo-cardio-facial syndrome: 30 Years of study. Dev Disabil Res Rev 2008;14:3-10. CrossRef

4. Ütine EG, Şimşek Kiper PÖ, Boduroğlu K. Microdeletion Syndromes (Review). Turkish Journal of Pediatrics 2012;55:42-51.

5. Leitch CA. Growth, nutrition and energy expenditure in pediatric heart failure. Prog Pediatr Cardiol 2000;11:195-202. CrossRef

6. Wang K, Yang Y, Shen F, Tao J, Xu H, Portnof JE, et al. Utilization of three-dimensional computed tomography for craniofacial phenotypic analysis in children with velocardiofacial syndrome. J Craniofac Surg 2009;20:2013-9. CrossRef

7. Widdershoven JC, Stubenitsky BM, Breugem CC, MinkvanderMolen AB. Outcome of velopharyngoplasty in patients with velocardiofacial syndrome. Arch Otolaryngol Head Neck Surg 2008;134:1159-64. CrossRef

8. Ha KM, Cleland H, Greensmith A, Chong D, Macgill K, Verhoeven A, et al. Submucous cleft palate: an often-missed diagnosis. J Craniofac Surg 2013;24:878-85. CrossRef 
9. Carotti A, Digilio MC, Piacentini G, Saffirio C, Di Donato RM, Marino B. Cardiac defects and results of cardiac surgery in 22q11.2 deletion syndrome. Dev Disabil Res Rev 2008;14:35-42.

10. Rauch R, Rauch A, Koch A, Zink S, Kaulitz R, Girisch M, et al. Laterality of the aortic arch and anomalies of the subclavian artery-reliable indicators for 22q11.2 deletion syndromes? Eur J Pediatr 2004;163:642-5.

11. Maeda J, Yamagishi H, Matsuoka R, Ishihara J, Tokumura M, Fukushima H, et al. Frequent association of 22q11.2 deletion with tetralogy of Fallot. Am J Med Genet 2000;92:269-72. CrossRef

12. van Amelsvoort T, Daly E, Robertson D, Suckling J, Ng V, Critchley $\mathrm{H}$, et al. Structural brain abnormalities associated with deletion at chromosome 22q11: quantitative neuroimaging study of adults with velo-cardio-facial syndrome. Br J Psychiatry 2001;178:412-9. CrossRef
13. Ricchetti ET, Hosalkar HS, Gholve PA, Cameron DB, Drummond DS. Advanced imaging of the cervical spine and spinal cord in 22q11.2 deletion syndrome: age-matched, double-cohort, controlled study. J Child Orthop 2008;2:333-41. CrossRef

14. Firth HV, Hurst JA. Deletions and duplications. Chapter 5: Chromosomes, In: Firth HV, Hurst JA (eds).Oxford Desk Reference Clinical Genetics. New York: Oxford Un. Pres 2005:520-22.

15. Nazlican H, Zeschnigk M, Claussen U, Michel S, Boehringer S, Gillessen-Kaesbach G, et al. Somatic mosaicism in patients with Angelman syndrome and an imprinting defect. Hum Mol Genet 2004;13:2547-55. CrossRef

16. Kitsiou-Tzeli S, Kolialexi A, Fryssira H, Galla-Voumvouraki A, Salavoura K, Kanariou M, et al. Detection of 22q11.2 deletion among 139 patients with Di George/Velocardiofacial syndrome features. In Vivo 2004;18:603-8. 